\title{
Research on the Roll Life Cycle Management Based on RFID
}

\author{
Yuan He, Zhihao Yin and Tian Chen \\ College of Engineering, Shanghai Polytechnic University, Shanghai 201209, China
}

\begin{abstract}
Rolls are the most important parts in the steel production industry. The roll lifecycle management method is put forward in this paper, so as to effectively control the production cost of rolling mills and improve the quality of rolling products. RFID (Radio Frequency Identification) technology and roll information life cycle management model are combined to integrate the existing workshop information to establish a platform for the sharing of roll production information. The ultimate goal is to guide the field use of rolls scientifically and standardize the roll, and improve the roll use rate.
\end{abstract}

Keywords-RFID; life cycle management; roll production information

\section{INTRODUCTION}

Product life cycle management refers to products from customer intention to product demand, and enterprises begin to manage product information management at various stages of product feasibility analysis, design products and process arrangements, then processing and manufacturing, product use and maintenance, and waste recycling.

It is extremely unfavorable for enterprises to collect data by using the traditional information collection means to improve the production management of the workshop. It is difficult to collect information from each link of the roll by using manual recording card. In many cases, due to the lack of efficient and effective data acquisition methods, enterprises can't get real-time information related to products. The roll data information is not comprehensive and inaccurate, it also can't be obtained in time, that makes the roll manufacturing enterprises and their related enterprises can't carry out real-time comprehensive coordination control on the internal and external resources related to the manufacturing process in the whole supply chain, which can't realize the fine management within the enterprise.

\section{PROCESS FLOW OF ROLL}

In order to realize the whole lifecycle management of roller, it is necessary to analyze the whole process of roll from design to scrap. On the basis of a comprehensive understanding of the basic information of the roller, it is necessary to analyze the relationship between the roll design, the roll manufacture and the roll use stage and other various departments. It is shown in Figure I.

The roll design department is designed according to the needs of the roll customers. This stage mainly focuses on customer demand and research of roll general process. On the basis of the analysis of the original experience and data, the roll production process is designed and converted into document.
At this stage, the roll type, usage and other related contents need to be considered. After the design is completed, pass the relevant documents to the manufacturing department.

Roll manufacturing enterprises produce rolls according to process requirement documents. At this stage, materials, production environment, process flow and so on are strictly required. Production enterprises must strictly follow the roll design and production plan, and record the basic information of roller production. After completion of the roll manufacture, the roller must be packaged and its basic information, grinding process and rules of use shall be issued to the customer.

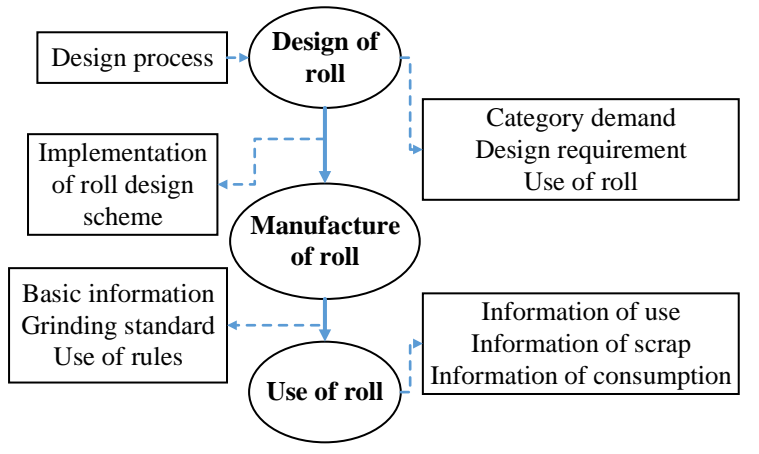

\section{FIGURE I. THE ROLL DESIGN AND PRODUCTION PROCESS}

The roll is used by the users according to the recommended data of the manufacturing enterprise. The roll is an important stage of the value of the roll. The roll is used many times in rolling line and the grinder, which will produce a lot of information of the use process. It is necessary to collect these data and send the information of using and scrap to the roll manufacturing enterprises, which can help them optimize the roll design process and improve the roll structure to improve and optimize the production process in order to enhance the production efficiency.

\section{Roll Life CyCle MANAGEMENT}

The full life cycle management of the roll is designed to ensure roll quality, price, performance, reliability, safety, service and the adaptability of the environment, which in order to provide a comprehensive and competitive product. According to the characteristics of the roller products and the actual working environment, the roll life cycle management system is designed according to the actual requirements. The PLM structure of the roll life cycle management system is shown in Figure II. 


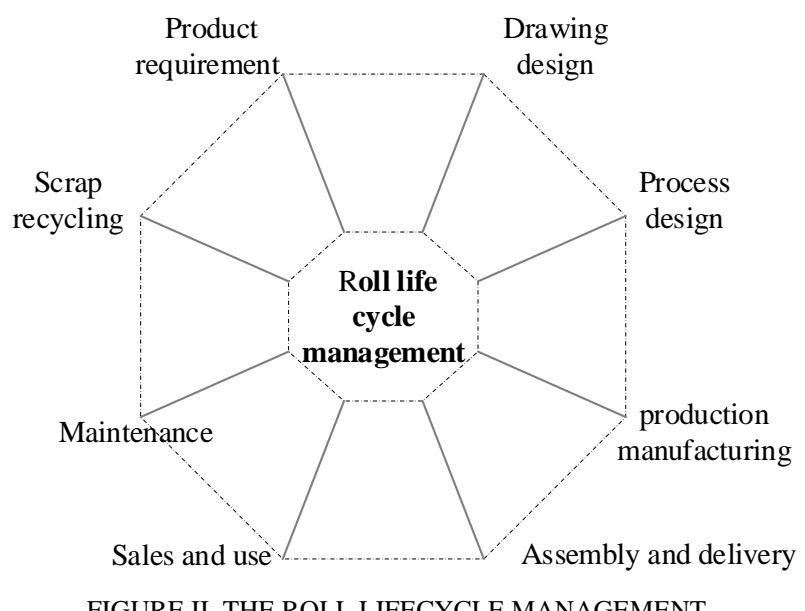

Demand for market requires product design and R \& D staff to consult relevant customers and understand information of product requirement. It includes basic information such as product performance, structure, environmental requirements of product, material usage and so on. As the market segmentation increases, the customer's personalized demand is increasing, and the information that needs is also expanded. In the analysis of the demand for the roll market, the requirements for packaging and transportation, processing technology are higher and cost control are getting more and more expensive.

The drawing design includes product structure diagram, product process plan and archive management. When designing archive management, product material selection, process arrangement, and technical requirements should be considered.

The process design is the arrangement of the process flow of the roll in manufacturing. In the process design, reference must be made to the relevant standards, and it should be compared with the original experience.

There are many kinds of information to be considered when manufacturing rolls, and the manufacturing process is complicated and varied. It includes manufacturing master plan, material usage requirement, process arrangement, capacity of workshop production and so on.

After production is completed, assembly and delivery is required. The rolls must be installed according to the requirements and plans of the rolls according to the assembly and dismantling requirements.

Maintenance management requires enterprises to take the use cycle, roll mileage and roll wear and consumption, and record relevant data and other key data to consideration when using rolls. Maintenance mainly includes two treatments, such as roll wear and repair, bearing cleaning and surface treatment.

Roll scrap recycling means that the roll can't be repaired after using a period of time, and it is necessary to analyze the scrap according to the conditions of roll scrap and the reuse of scrap, the cost accounting and the recovery.

\section{Model of MANAGEMENTSystem}

Roll management is to achieve effective management of roller data. RFID (Radio Frequency Identification)technology can be used for effective management and logistics tracking of rolls. The roll life cycle management system is combined with RFID technology to realize real-time updating and processing of roller online data. Referring to the architecture of internet of things (IOT) technology, roll management system can be divided into perceptive layer, network layer and application layer. Figure III shows the IOT model for roll lifecycle management.

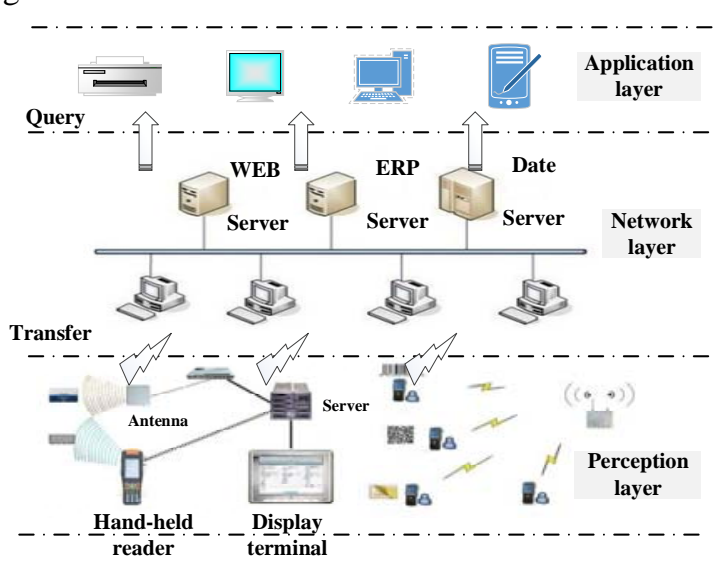

FIGURE III. THE IOT MODEL FOR ROLL LIFECYCLE MANAGEMEN

\section{IMPLEMENTATION OF LIFE CyCLE MANAGEMENT}

The basic information of the roll is provided by the roll production enterprise, including the basic information of the roll, it includes the material, the size and the processing technology, and the design of the grinding standard for the roll grinding, and the standard of repair judgment. The basic information of the roller determines the usage of the roller to a certain extent, and the material and processing method play a decisive role in the performance of the roller. The grinding machine is used to process the roller according to the grinding process. After the processing completed, the data is back to the basic information management module of the roll, and the roll diameter and surface quality of the roll have changed. The rolling line production workshop is the workshop of the roller. In this workshop, it is necessary to record the information of the roll up and down machine and detect the quality of the roller. The roll only can be sent in line, which surface quality is meeting the standard. Surface defect needs to be sent to the mill to repair, and it is necessary to process the scrap process for the serious damaged roll. These process data will be sent to the roll of lifecycle management system and then it will be stored in the database by the system.

The using and repairing data of the roll workshop are stored in the database, and the data are analyzed by the terminal server application. The results of the statistical analysis are delivered to the roll manufacturing enterprises in order to guide the production and manufacture of the rolls. According to the roller consumption data, the users can analyze the causes of roll loss and improve the existing production mode, which can improve the utilization of roll and avoid unnecessary roller consumption. It is shown in Figure IV. 


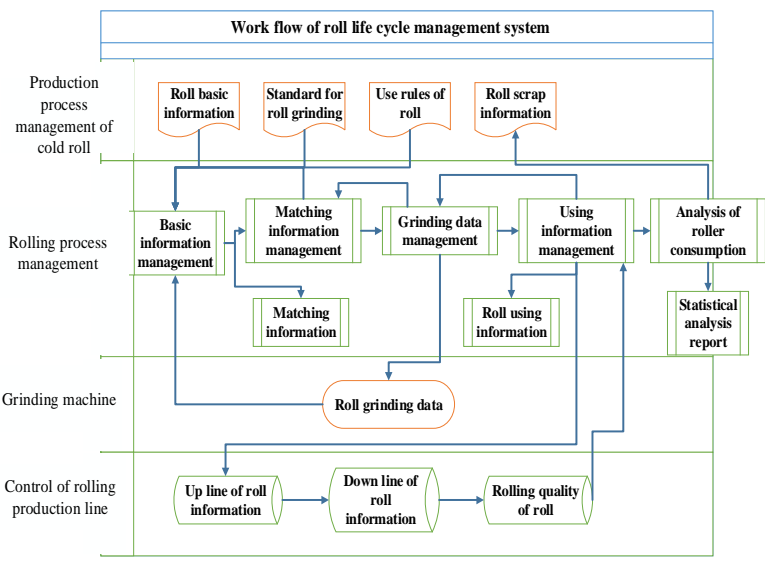

FIGURE IV.FUNCTION DIAGRAM OF ROLL SYSTEM

\section{CONCLUSION}

The roll life cycle management system can establish the data channel of the rolls of each system, which realizes the sharing of the roll information, and improves the management level of the roll with the aid of the existing production enterprise resources and equipment.

The roll lifecycle management system can realize the real-time management of roll information and realize the sharing of roller information, which can greatly improve the efficiency of workshop production. The system can replace the original manual management. The field production activities are more and more dependent on the computer management system, and demand of the reliability and stability of the system are becoming higher.

The production equipment needs continuous upgrading and expanding, and the interface of the peripheral system such as equipment system and detection system is also need to be further designed and optimized. The management of roll repair and roll attachments is integrated with the equipment system in order to improve the diagnosis level and repair level of the roll failure, and to further reduce the use failure of the rolls to prolong the use cycle of the roll, thus improving the use rate of the roll in the rolling line.

\section{ACKNOWLEDGEMENT}

This research was financially supported by the Key Discipline Project of Shanghai Polytechnic University (No. XXKZD1603) and Scientific and Technological Innovation Program of Shanghai Municipal Science and Technology Commission (No.15111102202).

\section{REFERENCES}

[1] H. S. Ning, R. Wang, Major project of RFID and National Internet of Thing, Machinery Industry Press, Beijing, 2015.

[2] L. Y. Zhang, Research on Aircraft Production and Maintenance Management System Based on RFID.J. Aeronautical Manufacturing Technology, 2011(19), 56-60.

[3] S. F. Wamba, A. Anand, L. Carter, A literature review of RFID-enabled healthcare applications and issues,Intel. J. Information Management. 2013 (5), 78-83.

[4] C. J. Yao, X. H. Chen, Research on RFID technology in the storage management of spare parts, J. Information of Micro-Computer, 2009(4), 23-27.
[5] K. Domdouzis, B. Kumar, C. Anumba, Radio-Frequency Identification (RFID) applications: A brief introduction. J. Advanced Engineering Informatics, 2006 (4), 87-92.

[6] H.Wu,Y.Zhu,H.Luo, Design of RFID interrogator based on warehouse management of logistics, J. Application of Electronic Technique. 2006(1), $18-22$ 